\title{
KINERJA BPD DALAM MENGIMPLEMENTASIKAN PERATURAN MENDAGRI NOMOR 110 TAHUN 2016 DI DESA SALARRI KECAMATAN LIMBORO KABUPATEN POLEWALI MANDAR
}

\author{
Ihsan Rizaldy', Sjuaib Hannan², Abdul Khalik³ \\ ${ }^{1}$ Prodi Ilmu Pemerintahan, Fakultas Ilmu-ilmu Sosial dan Ilmu Pemerintahan \\ Universitas Al Asyariah Mandar \\ Email: ihsanrizaldy7@gmail.com \\ ${ }^{2}$ Prodi Ilmu Pemerintahan, Fakultas Ilmu-ilmu Sosial dan Ilmu Pemerintahan \\ Universitas Al Asyariah Mandar \\ Email: sjuaibhannan2019@gmail.com \\ ${ }^{3}$ Prodi Ilmu Pemerintahan, Fakultas Ilmu-ilmu Sosial dan Ilmu Pemerintahan \\ Universitas Al Asyariah Mandar \\ Email: khalikmandar@gmail.com
}

\begin{abstract}
The purpose of this study is to find out how BPD'S performance in implementing the Minister of Home Affairs Regulation no. 110 of 2016 in Salarri Village, Limboro District, Polewali Mandar Regency. The study used descriptive methods and data were taken from sources by means of observation, interviews and documentation. The results showed that the BPD still did not understand its duties and functions due to the low education of BPD members so that their performance was also low. The allowance aspect is also low so that the needs of BPD members are not met and their duties are sidelined. The inhibiting factor is the lack of BPD knowledge about its duties and functions. Another factor is the government's lack of firmness in emphasizing the regulations that have been made.
\end{abstract}

\begin{abstract}
ABSTRAK
Tujuan dari penelitian ini untuk mengetahui bagaimana Kinerja BPD dalam Mengimplementasikan Peraturan Menteri Dalam Negeri No. 110 Tahun 2016 di Desa Salarri Kecamatan Limboro Kabupaten Polewali Mandar. Penelitian menggunakan metode deskriptif dan data diambil dari sumber dengan cara observasi, wawancara dan dokumentasi. Hasil penelitian menunjukkan bahwa BPD masih kurang memahami tugas dan fungsinya dikarenakan rendahnya pendidikan anggota BPD sehingga kinerja juga ikut rendah. Aspek tunjangan juga rendah sehingga kebutuhan anggota BPD tidak terpenuhi dan tugasnya dikesampingkan. Faktor penghambat yakni kurangnya pengetahuan BPD tentang tugas dan fungsinya. Faktor yang lain ialah kurangnya ketegasan pemerintah dalam melakukan penekanan terhadap peraturan yang telah dibuat.
\end{abstract}

Kata Kunci: Kinerja, Implementsi, BPD, Peraturan Mendagri. 


\section{PENDAHULUAN}

Undang-Undang Nomor 23 tahun 2014 tentang Pemerintahan Daerah khususnya pasal 1 angka 6 menyebutkan bahwa otonomi Daerah adalah hak, wewenang dan kewajiban daerah otonomi untuk mengatur dan mengurus sendiri urusan pemerintahan dan kepentingan masyarakat setempat dalam sistem Negara Kesatuan Republik Indonesia. Dalam menyelesaikan segala urusan pemerintahan yang ada di Desa, Kepala Desa akan dibantuh oleh aparatur Desa sesuai tugas dan fungsinya masing-masing. Sealain itu juga ada lembaga yang bertugas untuk melakukan pengawasan terhadap jalannya pemerintahan di Desa yaitu BPD selaku Badan Permusyawaratan Desa yakni sebagai wakil masyarakat di Desa.

Menurut Undang-undang Nomor 6 Tahun 2014 tentang Desa menyebutkan bahwa Desa adalah Desa dan Desa adat atau yang disebut dengan nama lain, selanjutnya disebut Desa, adalah kesatuan masyarakat hukum yang memiliki batas wilayah yang berwenang untuk mengatur dan mengurus urusan pemerintahan, kepentingan masyarakat setempat berdasarkan prakarsa masyarakat, hak asal usul atau hak tradisional yang diakui dan dihormati dalam sistem pemerintahan Negara Kesatuan Republik Indonesia (NKRI). Pengertian Badan Permusyawaratan Desa Berdasarkan Peraturan Pemerintah Nomor 72 Tahun 2005 Tentang Desa bahwa Badan Permusyawaratan Desa atau yang disebut dengan nama lain, selanjutnya disingkat BPD, adalah lembaga yang merupakan perwujudan demokrasi dalam pengawasan penyelenggaraan pemerintahan sebagai unsur penyelenggara pemerintahan desa. Sebagaimana dalam Peraturan Mentri Dalam Negri Republik Indonesia Nomor 111 Tahun 2014 tentang Pedoman Teknis Peraturan Desa Pasal 1 angka (4) :

BPD Berdasarkan Permendagri No. 110 Tahun 2016 Bab I tentang Ketentuan Umum pasal 1 poin 4, pengertian Badan Permusyawaratan Desa yang selanjutnya disingkat BPD atau yang disebut dengan nama lain adalah lembaga yang melaksanakan fungsi pemerintahan yang anggotanya merupakan wakil dari penduduk Desa berdasarkan keterwakilan wilayah dan ditetapkan secara Demokratis. Sebagai lembaga penampung aspirasi masyarakat BPD memiliki tugas utama yaitu melakukan pengwasan, membahas dan menyepakati Rancangan Peraturan Desa bersama Kepala Desa serta menampung dan menyalurkan aspirasi masyarakat.

Berdasarkan Undang-Undang No. 6 Tahun 2014 Tentang Badan Permusyawaratan Desa juga mengatur tentang bagaimana tugas dan fungsi BPD secara sepesifik dalam melaksanakan tugas dan fungsinya hal ini membuktikan bahwa BPD memiliki peran penting dalam pelaksanaan pemerintahan di Desa khususnya di Desa Salarri Kecamatan Limboro Kabupaten Polewali Mandar. Hal ini dibuktikan dengan adanya Peraturan Daerah Polewali Mandar No 3 Tahun 2015 Tentang Badan Permusyawaratan Desa. sehingga segala sesuatu yang ingin di sampaikan kepada Kepala Desa harus melalui BPD selaku penampung aspirasi. Namun yang terjadi di Desa Sallari BPD belum melaksanakan apa yang di 
inginkan Peraturan Menteri Dalam Negeri No 110 Tahun 2016 di karenakan masih banyak penyeimpangan yang terjadi di Desa .

Apa yang terjadi di Desa Salarri tidak menggambarkan sebagaimana kebijakan yang di buat oleh pemerintah di karenakan BPD di Desa Salarri belum mengetahui tentang alur maupun proses pembuatan Peraturan Desa. Bahkan Ketua BPD Desa Salarri menyatakan bahwa tanda tangan dirinya ditiru oleh orang lain, dan dirinya tidak mengetahui siapa yang menirunya. Secara tidak lansung bisa terlihat adanya ketimpangan yang terjadi yang tentunya dapat merugikan BPD itu sendiri maupun masyarakat.

\section{METODE PENELITIAN}

Penelitian ini merupakan penelitian deskriktif yakni penelitian yang berupaya mengungkapkan suatu masaalah dan keadaan sebagaimana adanya. Menggambarkan kinerja Kepala Desa dan BPD daram merumuskan peraturan di Desa Salarri Kecamatan Limboro Kabupaten Polewali Mnadar .

Sumber data diperoleh melalui wawancara, observasi maupun dokumentasi sedangkan sumber data sekunder yaitu data yang di peroleh dengan membaca buku literatur-literatur, dokumen resmi, peraturan perundang-undangan yang berkaitan.

Teknik pengumpulan data adalah merupakan usaha unutuk mengumpulkan bahan-bahan yang berhubungan penelitian yang dapat merupakan data fakta, gejala, maupun informasi yang valid (sebenarnya), relibele (dapat di percaya), data objektif (sesuai dengan kenyataan).

\section{HASIL PENELITIAN}

Lembaga Administrasi Negara Republik Indonesia (1999) menjelaskan bahwa terdapat lima indikator yang umum digunakan dalam hal mengukur kinerja yaitu:

1. Indikator kinerja input,

Indikator kinerja input adalah segala sesuatu yang dibutuhkan agar pelaksanaan kegiatan dapat menghasilkan keluaran yang ditentukan, misalnya dana, SDM informasi, sertakebijakan.

2. Indikator kinerja output,

Indikator kinerja output merupakan sesuatu yang diharapkan lansung dicapai dari suatu kegiatan yang berupa fisik maupun nonfisik.

3. Indikator kinerja outcome.

Indikator kinerja outcome adalah segala sesuatu yang mencerminkan berfungsinya penyelenggaraan kegiatan pada jangka waktu menengah.

4. Indikator kinerja manfaat.

Indikator kinerja manfaat yaitu sesuatu yang terkait dengan tujuan akhir dari pelaksanaan kegiatan.

5. Indikator kinerja dampak. 
Indikator kinerja dampak merupakan pengaruh yang ditimbulkan baik positif maupun negatif pada setiap indikator berdasarkan asumsi yang telah ditetapkan.

Kinerja sendiri oleh Rummler dan Brache dalam Sudarmanto (2009: 11) dikategorikan menjadi tiga bagian yakni kinerja organisasi, kinerja proses dan kinerja individu. Kinerja organisasi dan kinerja individu biasanya digunakan untuk mengukur sejauh mana sebuah organisasi dalam mencapai tujuannya, sedangkan kinerja proses biasanya digunakan oleh pelaku industri untuk mengukur sejauh mana proses pembuatan suatu produk mulai dari pengumpulan bahan baku, proses pembuatan hingga menjadi sebuah prodak. Mengingat BPD adalah sebuah kelembagaan politik atau organisasi politik penulis penulis beranggapan bahwa pengukuran menggunakan kinerja organisasi akan lebih efektif digunakan dalam penelitian ini.

BPD memiliki beberapa fungsi utama dalam berkinrja yaitu: fungsi pengawasan dalam rangka melakukan transformasi guna meraih perbaikan kualitas organisasi publik, perlu dilakukan pengawasan (control) terhadap seluruh tindakan dan akibat dari proses transformasi tersebut. Melalui pengawasan tersebut dapat diketahui penyimpangan-penyimpangan yang terjadi secara dini. Jika kekurangan dan kesalahan diketahui lebih awal maka akan dapat dilakukan perbaikan dan peningkatan dengan cepat, artinya semua permasalahan dapat diantisipasi. Dengan demikian akan menghindari terjadinya kebocoran dan pemborosan untuk membiayai hal-hal yang justru harus direvisi.

"Menurut pak Sukri Tawaran salah satu yang menjadi penghambat kinerja BPD dari tunjangan yang masih sangat terbatas yang hanya mendapat tunjangan 500.000/bulan dan diterima secara triulan.wawancara 16 april 2020.hal yang sama juga di ungkapkan oleh pak hamsa lubiz salasatu yang menjadi penyebab kami BPD bergerak dari segi anggaran dan tunjangan yang masih sangat kurang." (Wawancara, 16 April 2020)

Dalam menciptakan pemerintah desa yang lebih professional dituntut adanya hubungan dan kerjasama yang harmonis antara BPD dengan kepala Desa,selain keharmonisan anggaran juga sangat dibutuhkan dalam membagun Desa bukan dari segi aggaran desanya saja namun tunjangan maupun gaji harus disesuaikan dengan kebutuhan individu itu sendiri seperti aparatur Desa dan lain sebagainya. hal ini dimaksudkan agar terciptanya pelayanan pemerintah yang lebih baik.

"Merurut pak Sukri Tawaran BPD belum pernah mengajukan rancangan perdes dikarenakan ketidak mampuanya dalam melakukan pengajuan rancangan perdes dan ketua BPD haya sekali mengikuti pelatihan di luar provinsi.wawancara 16 april 2020 hal yang samama juga di ungkapkan oleh ketua BPD pak Hamza lubiz kempuan kami dalam membuat rancangan perdes masih sangat kurng." (Wawancara, 16 April 2020) 
Melihat wawancara menujukkan bahwa pelaithan BPD tetang tugas dan fungsinya sangatlah berperan penting dalam memajukan kesejahteraan Desa ,hal ini dikarenakan ketika kita meninjau funsi BPD itu sendiri, dimana ketiga fungsi tersebut dijalankan sebagaimana mestinya kita akan melihat masyarakat di Desa akan mendapat bantuan yang tepat sasaran dan terpenuhinya kebutuhan Desa.Menurut Peraturan Menteri Dalam Negeri No 110 Tahun 2016 tentang tugas dan fungsi BPD yakni;

BPD juga memiliki beberapa fungsi umun yang menjadi dasar terbentuknya BPD. Fungsi BPD diatur pada Peraturan Menteri Dalam Negeri No 110 Tahun 2016 Bab V tentang Fungsi dan Tugas BPD pasal 3 yaitu:

a) Membahas dan menyepakati rancangan perturan Desa bersama Kepala Desa.

b) Menampung aspirasi masyarakat

c) Melakukan pengawasan kinerja kepala Desa.

Tentunya dengan adanya kebijakan pemerintah tentang dasar dibentuknya BPD, diharapkan BPD mampu memberikan kenerja sesuai tugas dan fungsinya selaku Badan Mermusyawaratan Desa yakni sebagai penampung aspirasi masyarakat maupun sebagai mitra dalam bentuk mewujudkan kepentigan umum.

"Berdsarkan pengakuan ketua BPD Desa Salarri Pak Hamza telah menjabat selama 6 tahun lamanya dan sampai saat ini, iya dipilih secara ditunjuk lansung oleh Kepala Desa dikarenakan yang menjabat sebelum dirinya meninggal dunia sehingga digantikan oleh ketua BPD saat ini, ketika ditanya tentang bagaimana kinerjanya selama iya menjabat beliau menjawab iya hanya menjadi penegah ketika ada permasalahan antara masyarakat contohnya permasalahan sengketa iya beliau selalu menyelesaikan masalah tersebut sebagai penegah antara masyarakat agar tidak terjadi sesuatu yang tidak di inginkan. "(Wawancara, 16 april 2020)

Selain itu Pak Hamza juga ditanya mengenai prgram kerjanya beliau menjawab bahwa

"BPD Desa Salarri tidak memiliki program kerja sama sekali sejak beliau menjabat maupun sebelum nya,sehingga BPD Desa Salarri tidak memiliki pedoman dalam melaksankan kineja dan beliau mersa bahwa keberadaanya hanya sebatas formalitas semata hal ini juga dikarenakan masyarakat tidak ingin mendegarkan apa yang di himbaukan oleh BPD menurut Pak Hamza selaku Ketua BPD”. (Wawancara, 16 April 2020)

Namun ada beberapa faktor yang menjadi penghambat terlaksanya tugas dan fungsi BPD sehingga tidak dapat berkinerja sesuai yang diharapakan yakni kurangnya pemahaman tentang tugas dan fungsi BPD serta anggota BPD tidak dibekali tentang pemahaman organisasi sehingga tidak memiliki program kerja yang seharusnya menjadi sebuah acuan untuk berkinerja. Menurut ketua BPD Desa Salarri HAMSA LUBIS; 
"Anggaran juga menjadi pengghambat yakni anggaran untuk BPD hanya Rp 15.000 yang menurutnya masih sangat kurang. Sehinnga ketua BPD Desa Salarri berharap adanya peningkatan dari segi anggaran dan tunjangan kepada anggota BPD agar dapat melakukan sebuah kegiatan". (Wawancara, 16 April 2020)

Sekdes Nur haisah Desa Salarri mengatakan bahwa

"Anggota BPD memiliki ruangan dalam berkantor di kantor Desa namun yang menjadi pertanyyan apa yang di kerjakan BPD di kantor sedangkan ketua BPD sendiri menyatakan tidak pernah berkinerja selama enam tahun menjabat, selain itu ketua yang menjabat saat ini hanya pengganti ketua yang terdahulu yang meninggal dunia enam tahun yang lalu, kemudian ketua BPD saat ini yang meggantikan ketua BPD yang lama juga merupakan anggota BPD yang ditunjuk sebagai ketua BPD Saat ini jadi beliau tau persis tentang bagaimana perjalanan BPD di Desa Salarri “. (Wawancara, 16 April 2020).

Menurut penjelasan pak SUKRI TAWARAN selaku kepala Desa Salarri bahwa;

"Berkaitan dengan kemampuan yang dimiliki oleh ketua BPD secara pengetahuan dalam melaksanakan tugas dan fungsinya pelatihan dalam perjalanan dinas, sementara itu pengakuan ketua BPD tidak banyak mendapatkan ilmu tentang tugas dan fungsinya karena pelatihan itu hanya di ikuti satukali saja te'rlebih pihak kecamatan tidak pernah melakukan pelatihan terhadap anggota BPD berdasarkantugas dan fungsinya". (Wawancara, 16 April 2020)

Ketika melihat masaalah yang terjadi di Desa Salarri kita tidak melihat kinerja dari BPD hal ini dikarenakan tidak adanya program kerja lantas bagaimana kita akan melakukan sebuah evaluasi kinerja adalah penilaian pelaksanaan tugas (seseorang atau sekelompok orang atau unit kerja organisasi atau perusahaan,

\section{KESIMPULAN}

Berdasarkan hasil penelitian yang telah di lakukan di Desa Salarri dapat disimpulkan bahwa; BPD Desa Salari masih sangat memerlukan banyak pengetahuan melalui palatihan serta mempelajari tugas dan fungsinya dengan berdasarkan Permendagri No. 110 tahun 2016. Hal ini dikarenakan BPD Desa Salarri tidak mengerjakan tugas dan fungsinya seperti menyampaikan asprasi masyarakat, membuat rancangan perdes serta melakukan pengawasan terhadap jalannya pemerintahan di Desa. hal ini membuat masyarakat tidak menyaadari pengaruh degan adanya BPD dalam pembagunan Desa dan tidak mendapat dukungan dari Desa. Adapun faktor penghambat yakni kurangnya pengetahuan BPD tentang tugas dan fungsinya serta kurangnya tunjangan yang membuat pendapatan tidak dapat menjamin kebutuhan sehingga tugasnya sebagai BPD 
menadi hal yang dikesampinkan. Sealain itu faktor yang berpengaruh ialah adanya hubungan kekeluargaan yang membatasi untuk mempertahankan hak sebagai BPD atau mitra Desa.

\section{SARAN}

Adapun saran yang ditawarkan dalam hasil penelitian ini agar dapat menjadi sumber pengetahuan kita kedepanya yakni: dalam upaya kesejahteraan di Desa tentunya BPD memiliki peran penting sehingga peningkatan mutu sangat dibutuhkan melalui adanya pelatihan khusus yang di berikan untuk BPD. Sehingga BPD dapat melaksanakan tugas dan fungsinya sebagai mana mestinya. Penambahan anggaran maupu gaji juga sangat membatu bagi BPD dalam melaksanakan tugas dan fungsinya agar mereka dapar fokus dalam mengerjakan apa yang seharusnya mereka kerjakan.

\section{DAFTAR PUSTAKA}

A.A Anwar Prabu Mangkunegara. (2005). Manajemen Sumber daya ManusiaPerusahaan. Bandung : PT Remaja Rosdakarya

As'ad. Moh., (2003). Psikologi Industri. Libery. Yogyakarta Masrukhin dan

Waridin, 2006. Pengaruh Motivasi Kerja, Kepuasan Kerja, Budaya Organisasi Dan Kepemimpinan Terhadap Kinerja Pegawai.

Browne, Wildavsky. (2004:70) mengemukakan bahwa "implementasi adalahPerluasan aktivitas yang saling menyesuaikan.

Dwiyanto, Agus, dkk. (2003). Konflik di Era Otonomi Daerah dalam "Reformasi Tata Pemerintahan dan Otonomi Daerah", PSKK-UGM, Yogyakarta.

Erni TrisKurniawan, Sule dan Saefullah, 2005. Pengantar Manajemen,. Jakarta. Prenada Media Jakarta.

Juliantara, Dadang, 2005. Peningkatan Kapasitas Pemerintah Daerah Dalam Pelayanan Publik. Pembaharuan. Yogyakarta.

Meokijalt, (2008:22), Administrasi Perkantoran. Bandumg: Mandar Maju.

Mc Shane \& Ginow, 2007. Organizational Behavior fourth Edition, Mcgraw HillInternasional edition,2008. Perntice Hall.

Nining Haslinda Zainal, Analisis Kesesuaian Tugas Pokok dan Fungsi denganKompetensi Pegawai pada Sekretariat Pemerintah Kota Makassar,Universitas Hasanuddin: Skripsi, 2008.

Robbin, Stepen P. (2003). Organizational behaviour: Alih Bahasa. Jakarta:

Kelompok Gramedia.

Robbin, Stephen, 2006, "Perilaku Organisasi”, Prentice Hall, edisi kesepuluh 
Rivai, Veithzal dan Basri, 2005. Performance Appraisal: Sistem Yang Tepat Untuk Menilai Kinerja Karyawan Dan Meningkatkan Daya Saing Perusahaan. Rajagrafindo Persada. Jakarta

Simanjuntak, Payaman J. (2005:105). Manajemen dan Evaluasi Kinerja. Lembaga saparin, SumberPenerbit FEUI,Jakarta.

Soelaiman,(2007:112), Manajemen Kinerja ; Langkah Efektif untuk Membangun,Mengendalikan dan Evaluasi Kerja, Cetakan Kedua, Jakarta: PT.Intermedia Personalia Utama`

Soekanto, Soerjono. (2004). Sosiologi Suatu Pengantar. Jakarta:Raja Grafindo Persada.1986, Tata Pemerintahan Dan Administrasi Pemerintah Desajakarta: Ghalia Indonesia.

Simbolon, Maringan. Masri. 2004. Dasar-Dasar Administrasi dan Manajemen. Jakarta: Ghallia Indonesia

Sulistiyani. Ambor T. Dan Rosidah, 2003. Manajemen Sumber Daya Manusia.Graha Ilmu. Yogyakarta.

Srimindari, 2006. Balanced Scorecard Sebagai Alternatif untuk Mengukur kinerja.STIE Stikubankhttp.duniaesai.com.semarang.

Tika p., 2006 Budaya Organisasi Dan Peningkatan Kinerja Perusahaan. PT Bumi Aksara. Jakarta

Uno, Hamzah dan Nina Lamatenggo. 2012. Teori Kinerja dan Pengukurannya. PT. Bumi Aksara. Jakarta.

Widjaja, 2003, Otonomi Desa Merupakan Otonomi Yang Asli, Bulat dan Utuh,Jakarta: PT Raja Grafindo PersadaZainal,

Nining Haslinda. 2008. Analisis Kesesuaian Tugas Pokok dan Fungsi Dengan kompotensi pegawai pada sekretariat pemerintah kota makassar. Makassar:FISIPOIL

Permendagri No. 110 Tahun 2016 Tentang fungsi dan tugas BPD

Undang-undang No. 32 Tahun 2004 tentang Pemerintah Daerah

Undang-undang No. 23 Tahun 2014

Permendagri No. 11 Tahun 2016 tentang tugas dan fungsi BPD

Peraturan pemerintah No. 72 Tahun 2015 